\title{
Western disturbances seen with AMSU-B and infrared sensors
}

\author{
DileEP M PURANIK* and R N KAREKAR \\ Department of Atmospheric and Space Sciences, University of Pune, Pune 411 007, India. \\ *e-mail: dileepmp@unipune.ernet.in
}

\begin{abstract}
Western disturbances (WD) of winter and pre-monsoon seasons are the important sources of rainfall in the Indo-Gangetic plains. WDs are troughs or circulations in the westerly winds modified by the Himalayas. Operationally, WDs are monitored using infrared (IR) and water vapour (WV) images. Advanced Microwave Sounding Unit-B (AMSU-B), flying onboard the NOAA satellites, also allows WDs to be monitored in five microwave frequencies. Two are in water vapour window $(89,150 \mathrm{GHz})$ and three are absorption channels (centred at $183.31 \mathrm{GHz}$ ). Unlike the top of cloud view in IR or WV, AMSU-B radiances show the effect of moisture and hydrometeors in different layers.

Two cases of WD (17 April 2001 and 18-19 February 2003) are discussed using the microwave data from AMSU-B and the IR and WV data from Meteosat-5. The aim here is to demonstrate the skill of AMSU-B in delineating structure of WDs. In particular, the cold intrusion and the moist conveyor belts are examined. It was found that the multi-channel view of the AMSU-B permits a better understanding of the moist structures seen in the conveyor belts.

The $\grave{a}$ trous wavelet transform is used to clearly bring out mesoscale features in WDs. AMSU-B brings out intense convection as a large depression of BTs $(>50 \mathrm{~K})$ at $150 / 176 \mathrm{GHz}$, cirrus and moist bands at 180/182 GHz. Mesoscale convection lines within WDs that last short time are shown here for the first time only in the AMSU-B images. Large-scale cirrus features are separated using the $\grave{a}$ trous wavelet transform.

Lastly, it is shown that there is a good likeness in the rain contours in the 3-h rain 3B42 (computed from TRMM and other data) to AMSU-B depressions in BT. Overall, AMSU-B shows better skill in delineating the structure of clouds and rain in WDs.
\end{abstract}

\section{Introduction}

\subsection{Western disturbances (WDs)}

The WDs (Rao and Srinivasan 1969) are the main source of precipitation in winter and premonsoon seasons over the Indo-Gangetic plains. During these seasons about $4-5$ WDs occur per month over NW India. They are baroclinic weather systems (Holton 1992) moving within the westerly wind regime. The main component of these systems is water vapour from the Arabian Sea rising along isentropic surfaces. WDs are not extratropical cyclones (Bader et al 1995) but are unique to the Indian subcontinent.

In an extratropical system, an anticyclonically curved warm conveyer belt brings in warm moist air to the centre of the system. The warm conveyor belt (WCB, Browning 1986; Bader et al 1995) is an isentropic flow initiating in the planetary boundary layer in the subtropics and moving upwards and towards higher latitudes, almost parallel to the surface front. The realisation of such conveyor belts in the satellite images has been termed atmospheric rivers of moisture. Such WCBs are many hundreds of kilometres long. This warm air is undercut

Keywords. Western disturbances; microwaves; infrared; AMSU-B; atmospheric sciences; remote sensing. 
by (typically north-westerly) cold conveyor belt of similar dimensions. At the boundary of the cold and dry conveyor belts, vertical circulations are set up, producing convection.

In contrast, a WD is smaller, of the order of five degrees latitude in size. It develops within an existing trough in the belt of subtropical westerly wind and intensifies on passage across the Suleiman ranges in Pakistan. Temperature and humidity gradients are not steep in WDs and therefore WDs do not show fronts. In fact, given the weak temperature gradients over the (Indian) subtropical region, moist conveyor belts (MCB) (Bao et al 2006; Knippertz and Martin 2007) occur instead of WCB. Southwesterly wind ahead of the trough brings in moisture from the Arabian Sea. The western Himalayas lie almost normal to this moist wind ahead of the trough. WDs are retarded and modified during their passage across the western Himalayas. The Sub-Tropical Jet stream (STJ) is often poised over these westerly troughs. Behind the trough, the cold and dry upper tropospheric wind crosses southwards. This is a cold air intrusion into the WD. The STJ provides the necessary upper level divergence for the intensification of the WD.

During the passage of a WD, the moist air ascending over the western Himalayas produces thick and cold cirrus over the Himalayas which do not have significant rain or rain rates. Beneath this cirrus canopy, short life mesoscale cloud structures develop that produce significant rain. In both IR and $\mathrm{WV}$ images, the cold canopy leads to overestimation of the raining areas (Kidder and Vonder Haar 1995) in a WD.

\subsection{Sensing WDs from satellites}

Operationally, the WDs are monitored in thermal infrared (10.5-12.5 $\mu \mathrm{m}$, IR) and water vapour absorption $(6.7 \mu \mathrm{m}, \mathrm{WV})$ bands from geostationary satellites such as INSAT and Meteosat-5. The latter had a high spatio-temporal sampling frequency ( $5 \mathrm{~km}, 30 \mathrm{~min}$ ), permitting close monitoring of weather systems. However, only the cloud-top radiances are sensed in IR. In the WV band, radiances from the mid-tropospheric moist layer and cloud tops above the moist layer are visible.

The problem of not being able to see beneath cloud tops and not seeing moisture in various layers, faced by visible and infrared sensors, may be alleviated with microwaves. The earlier microwave sensors had coarse resolutions (25-60 km). Even with this limitation, the Special Sensor Microwave/Imager was able to sense the MCBs (Bao et al 2006). Since 1998, with the launch of the Advanced Microwave Sounding Unit-B (AMSU-B), with a $16 \mathrm{~km}$ nadir resolution in five channels, clouds and moisture can be sensed with higher fidelity.

\subsection{Problem statement}

From the discussion above it is apparent that the area of ascent in the MCB results in medium and high clouds. At the boundary of moist and dry air, instability occurs since the moisture and temperature gradients are large. Accurately locating and finding the extent of various cloud-types is important for locating the latent heat releases that drive the disturbance and assessing the rain rates. These considerations lead to the first aim of this paper.

- To compare the depiction of the cold intrusions and MCBs in the five-channel AMSU-B data and the IR or WV data (see section 4).

The other two complementary aims are as follows.

- To delineate mesoscale structures within the WDs with wavelet transform (WT) as an additional tool (see section 5).

- To show that wavelet transformed AMSU-B images have better likelihood to the TRMM 3-h rain data for $\mathrm{WD}$, than $\mathrm{IR} / \mathrm{WV}$ images (see section 6).

This paper is organised as follows. Data and its scale analysis are discussed in section 2. For scale analysis we introduce a new variant of WT termed the à trous WT (ATWT, Starck et al 1998; Puranik and Karekar 2004). We have selected two typical cases for this study. In section 3, the synoptic environment of two cases of WD (17 April 2001, 19 February 2003) is discussed. A comparative study of conveyor belts using IR, WV and AMSU-B data, is made in section 4. Section 5 brings out the advantage of AMSU-B (and the scale analysis of the AMSU-B data) for bringing out mesoscale features of WDs. Section 6 discusses rain in WDs. Section 7 has remarks on WD analysis and concludes this work.

\section{Data and scale analysis}

\subsection{Sensors}

The IR and WV data are from the Meteosat-5. These have been radiometrically and geometrically corrected by EUMETSAT. We have carried out geo-location and conversion of digital counts to BTs. The range of BTs covered with a grey-scale in IR and WV data is between $318 \mathrm{~K}$ and $190 \mathrm{~K}$. Each grey-shade corresponds to an $8 \mathrm{~K}$ interval.

The response of the WV band depends on the sensor bandwidth, the sensor zenith angle and the 

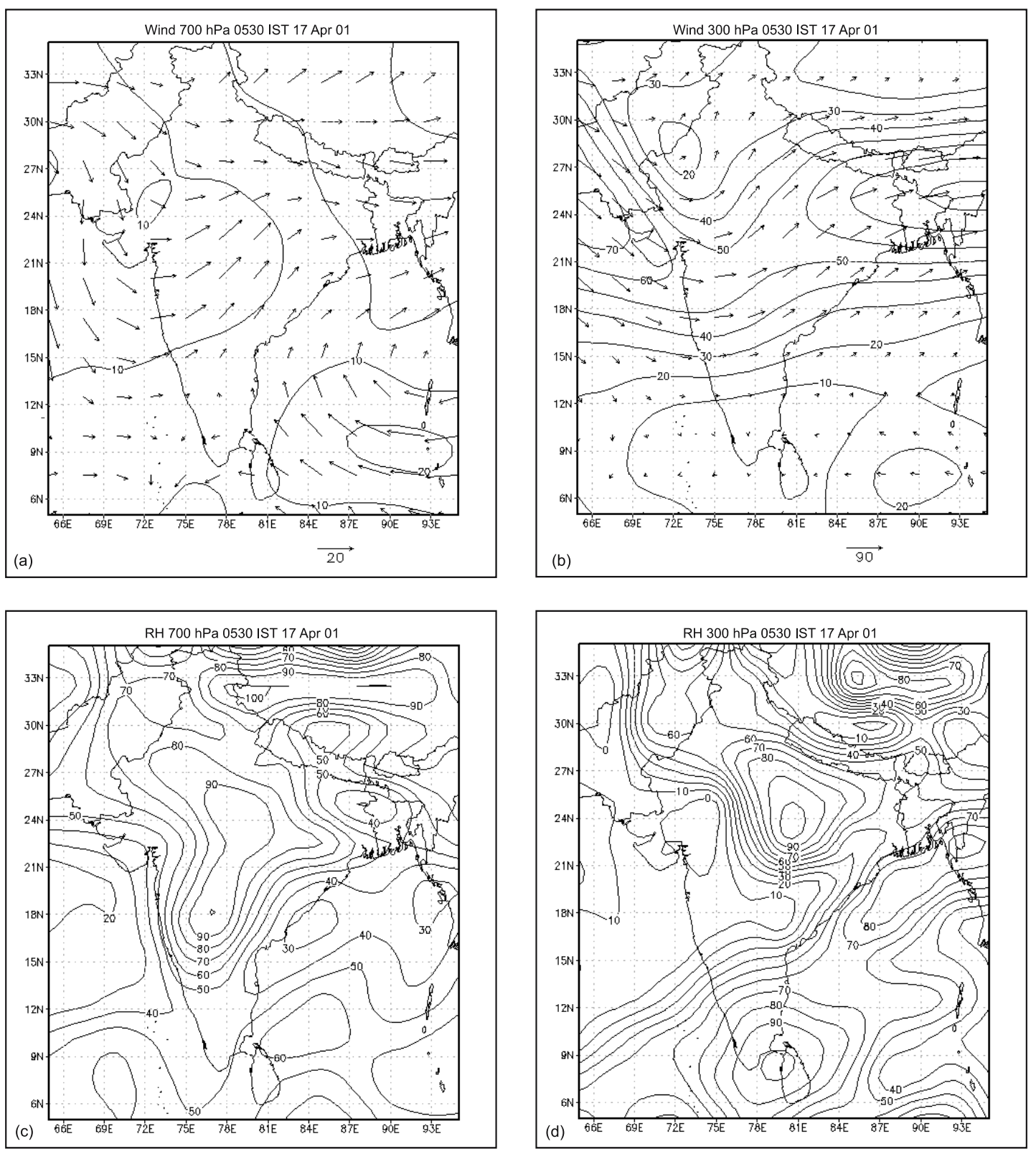

Figure 1. Synoptic situation at 0530 IST on 17 April 2001. (a) Upper winds and isotachs are seen at $700 \mathrm{hPa}$, (b) at $300 \mathrm{hPa}$ levels, (c) RH at $700 \mathrm{hPa}$ and (d) at $300 \mathrm{hPa}$. The shapes of the regions of steep moisture gradient are similar but displaced by the dry air intrusion.

intervening atmosphere. In the case of Meteosat-5, the weighting function (Kidder and Vonder Haar 1995) peaks between 350 and $400 \mathrm{hPa}$ in midlatitude summer atmospheres (Roca et al 2001).

The AMSU-B instrument flew or presently flies onboard many NOAA satellites (N-15, 16, 17 and 18). Each scan line has 90 pixels covering $2120 \mathrm{~km}$ (Goodrum et al 2000). Sensing channels are at $89,150,183.3 \pm 1,183.3 \pm 3$ and $183.3 \pm 7 \mathrm{GHz}$. The latter three channels are referred to as 182 , 180 and $176 \mathrm{GHz}$. The first two channels, 89 and $150 \mathrm{GHz}$ are in atmospheric windows while the other three are in the $183 \mathrm{GHz}$ absorption band allowing an assessment of water vapour. The
AMSU-B digital counts are converted to BTs. The 90 pixels in each scan line were re-sampled to 136 pixels per line to correct the image distortion. The BTs are shown as images using a grey-scale with $3 \mathrm{~K}$ intervals.

\subsection{Data sources}

Meteosat-5 IR and WV data at $5 \mathrm{~km}$ spatial and $30 \mathrm{~min}$ temporal resolution is obtained from EUMETSAT archives. AMSU-B data is from NOAA CLASS Archive. In section 6, three hourly rain (in mm) data for $0.25^{\circ} \times 0.25^{\circ}$ cells from the Tropical Rain Measuring Mission (TRMM) 

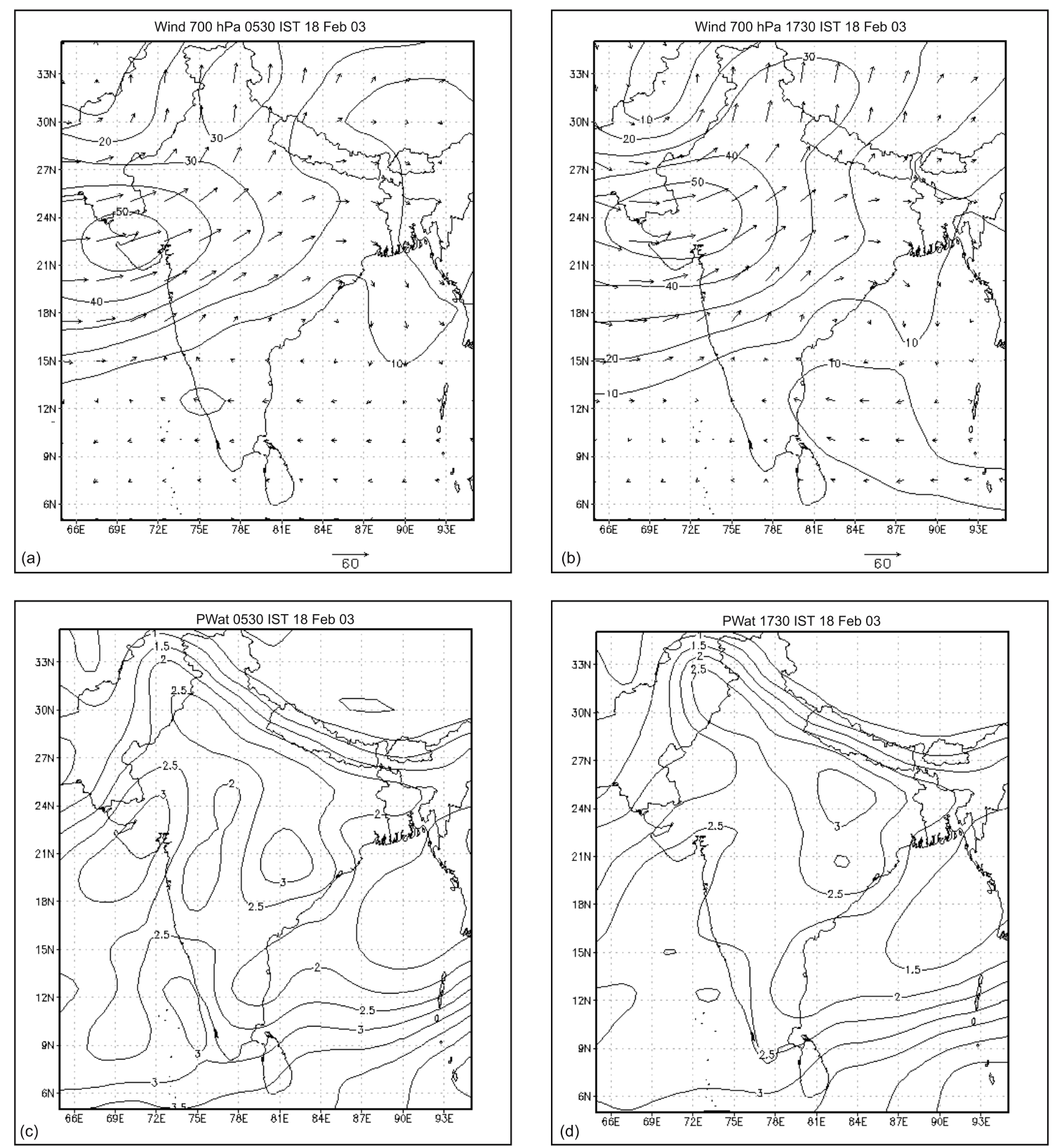

Figure 2. Synoptic situation at $700 \mathrm{hPa}$ on 18 February 2003. (a) Upper winds and isotachs are seen at 0530 IST and (b) at 1730 IST. (c) and (d) show column precipitable water at 0530 IST and 1730 IST respectively. Advection of moisture into Rajasthan is apparent.

3B 42 algorithm is used for comparison with AMSU-B.

\subsection{Depression in $B T s(d B T)$ due to clouds and cloud systems}

The AMSU-B or infrared images show objects against background radiances either from land or ocean. The background radiances are reduced (or depressed) very little in IR, significantly in WV and microwaves, by moisture. Significant clouds cause large reduction in radiance, i.e., a large dBT.
The AMSU-B brightness temperature (BT) contrast and size signatures for different cloud types are caused by the distribution of water vapour and hydrometeors such as cloud droplets, raindrops, ice, graupel and hail resulting in absorption or scattering within the cloud. Reduced radiances show as lower BTs. Therefore, dBT is important in our analysis. Gheiby et al (2003) have used BT and dBT information in Artificial Neural Networks for cloud recognition purpose.

The BT at 89 and $150 \mathrm{GHz}$ are related to surface emission, absorption in the lower layers of atmosphere and scattering by water droplets 

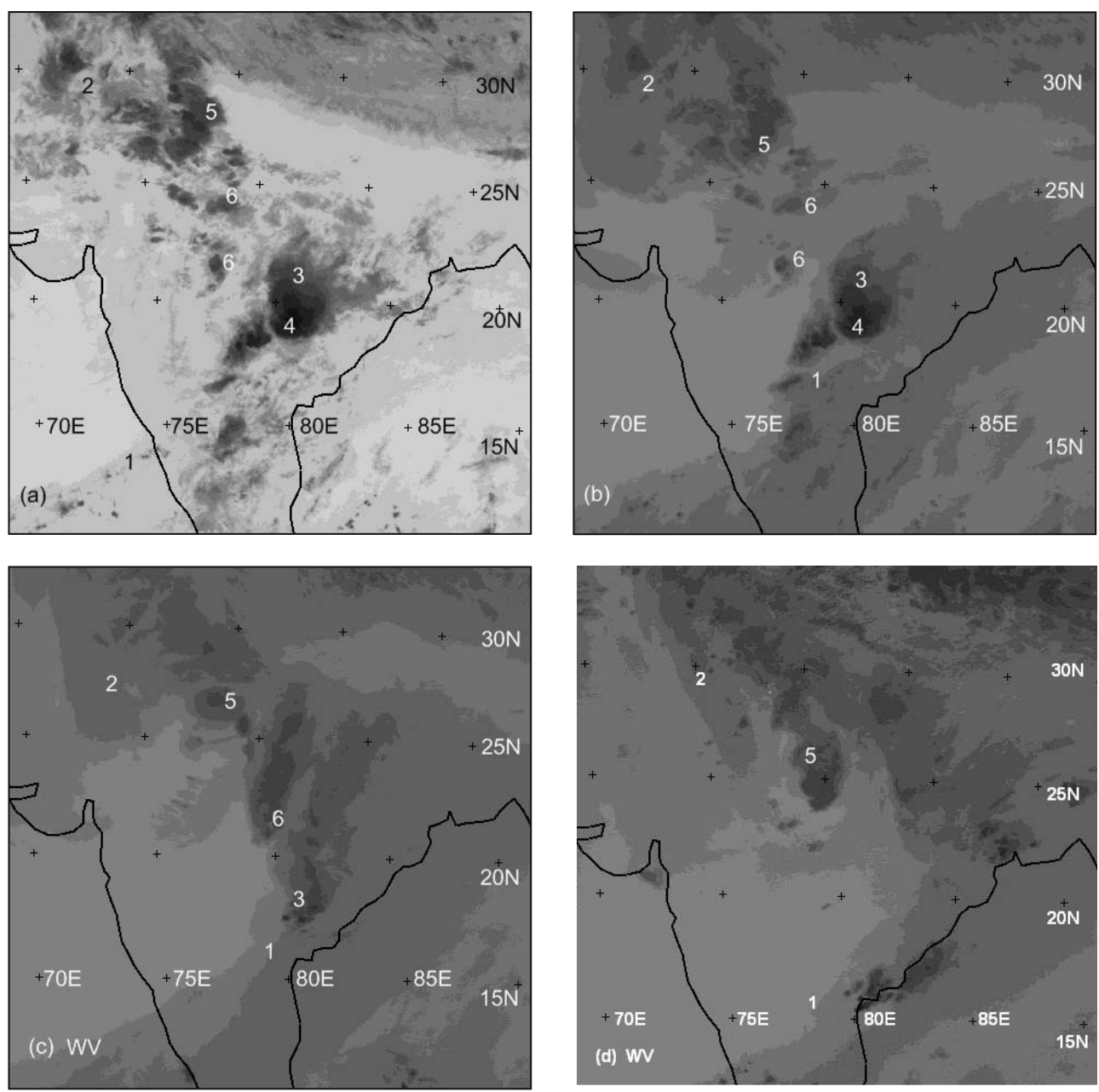

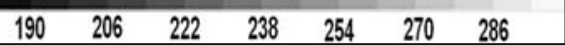

Figure 3. The evolution of the WD on 17 April 2001. (a) IR and (b) WV images at 0230 IST. (c) and (d) are the WV images at 0730 and 1430 IST. Labels are explained in the text. Grey-scale shows BTs in all IR and WV figures.

and ice crystals. The $183.31 \mathrm{GHz}$ channels show only absorption and scattering due to higher (ice dominated) clouds and moist layers. These characteristics produce five different views of any deep weather system.

The magnitude of dBT depends on the absorption as well as scattering characteristics of the atmospheric constituent in the path of the microwave radiation. Water vapour within, say, $1-2 \mathrm{~km}$ of the surface not only absorbs radiation but also radiates at a high rate giving overall a small dBT in 89 and $150 \mathrm{GHz}$; other channels being unaffected. On the other hand water vapour in the mid-troposphere radiates, adding to the BT. Water vapour in the upper troposphere shows as lower BT at 180 and $182 \mathrm{GHz}$. Water droplets being large in size with respect to the $89-176 \mathrm{GHz}$ radiation, does not cause significant scattering, only absorption. The overall effect on dBT is small, but positive. Melting ice in thunderstorm bright bands or graupel on the other hand cause very strong scattering, causing large dBTs. On the other hand large upper tropospheric ice crystals cause significant scattering and very low dBT in all channels. Overall, only large, melting ice plates and graupel cause strong scattering and low BTs. Cirrus do not cause significant dBT.

Muller et al (1994) and later Skofronic-Jackson et al (2002) found significant $(>70 \mathrm{~K})$ dBTs in AMSU-B frequencies over convective clouds. The $150 \mathrm{GHz}$ channel was most sensitive to hydrometeors $(\mathrm{dBT}>90 \mathrm{~K})$. The dBTs are extracted by wavelet transform and their values can identify processes causing scattering.

\subsection{Spatial scale analysis with à trous wavelet transform}

Weather systems such as WDs are made up of features of different sizes and lifetimes. Lifetime of 
a feature is important for mesoscale forecasting. This, in turn, is related to its size through the group velocity. To extract features of WDs, of finite size and lifetime, multi-scale analysis such as the wavelet transform (WT) is useful.

A special WT called à trous (ATWT, Shensa 1992) is used in the present work. Unlike other WT, it is non-decimating, i.e., the dimension of any wavelet component image is the same as that of the original data. Therefore, the ATWT output as scale $k$ can be interpreted as the depression in $\mathrm{BT}$ (dBT) at scale $k$ in the image with respect to scale $k-1$. ATWT is discussed by Starck et al (1998). Puranik and Karekar (2004) have discussed its implementation specifically for the weather satellite images. To meet the requirement of having reasonably uniform background, $64 \times 64$ pixels, i.e., $1024 \times 1024 \mathrm{~km}$ sub-images of the AMSU-B images are used when applying the $\grave{a}$ trous WT.

At every stage of the WT, the objects doubled in scale from the previous stage are successively revealed. Since information is not lost in decimation, the equivalence of pixel values at each scale with radiance is be maintained. A very brief outline of the ATWT is given in Appendix. We now utilise the data and analysis methods described above to discuss two typical WDs.

\section{A synoptic view of the two WDs}

As indicated in section 1.3 we have selected WDs of 17 April 2001 and 18-19 February 2003 for detailed study. The Indian Daily Weather Summary for 16 April 2001 reported a cyclonic circulation over Punjab till $5 \mathrm{~km}$ and an upper air trough with its axis at $9.5 \mathrm{~km}$ at $74^{\circ} \mathrm{E}$ seen north of $15^{\circ} \mathrm{N}$. On 17 April, the cyclonic circulation persisted. The upper air trough reached $75^{\circ} \mathrm{E}$ at $9.5 \mathrm{~km}$. During the day the upper air trough moved from $75^{\circ} \mathrm{E}$ to $78^{\circ} \mathrm{E}$. On 18 April, the upper air trough moved to $80^{\circ} \mathrm{E}$ and weakened.

Prior to this event, there had been widespread and intense convection south of $15^{\circ} \mathrm{N}$ due to the passage of an easterly wave. Moisture was raised aloft and was moving northwards on 16 April. Dry air entered the region from northwest, behind the trough and from north of the subtropical jet on 16 April. It spread south and eastward on 17 April. Figures 1(a) and (b) show the winds at 700 and $300 \mathrm{hPa}$ respectively, at $0530 \mathrm{IST}$ on 17 April. In both the figures the northerly wind direction behind the trough is notable. Figures 1(c) and (d) show relative humidity at 0530 IST on 17 April at $700 \mathrm{hPa}$ and $300 \mathrm{hPa}$. Depending on the dry air density and wind speed, the moist regions are differentially displaced to east showing the relative humidity at 700 and $300 \mathrm{hPa}$ respectively.
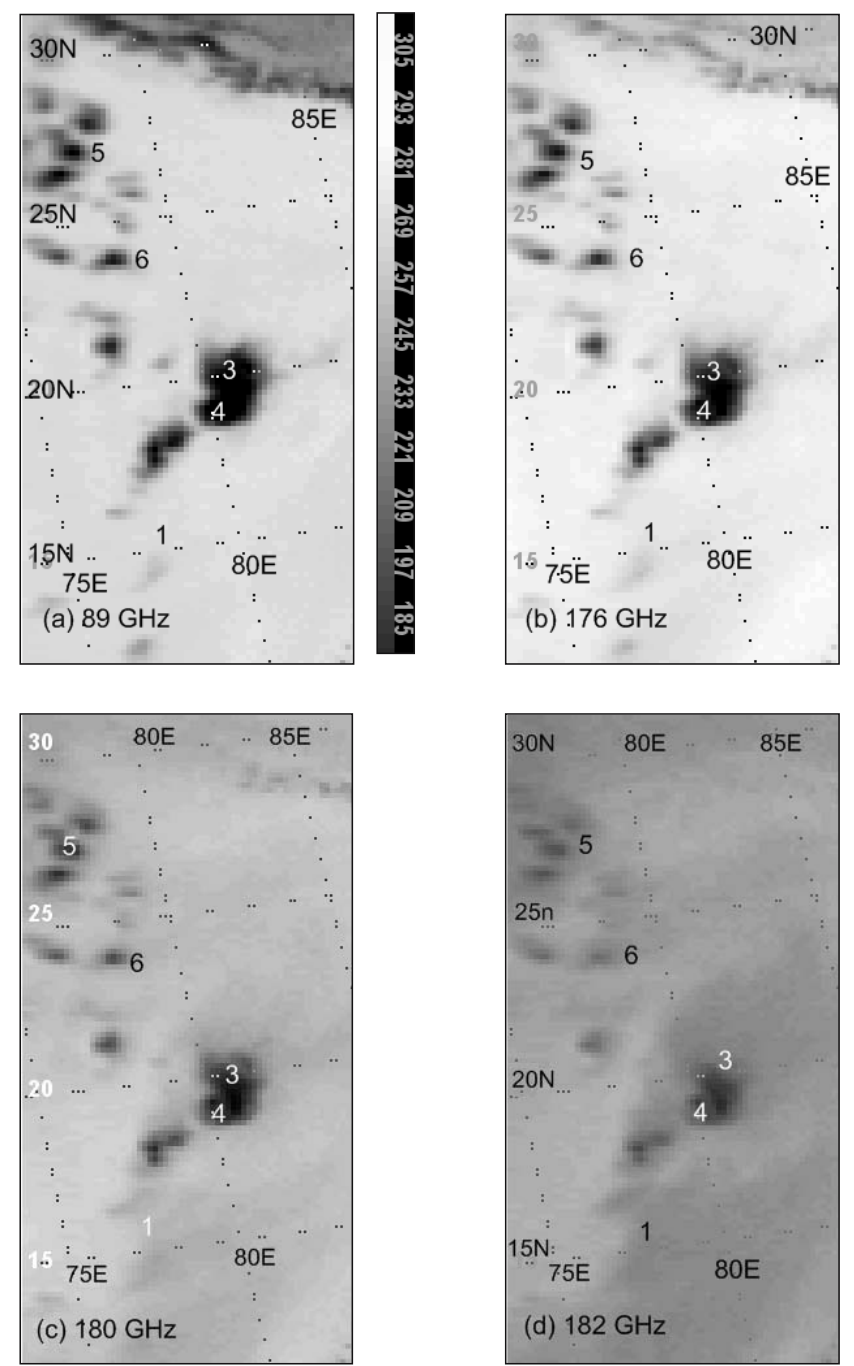

Figure 4. The AMSU-B images at 0230 IST on 17 April 2001; (a) shows $89 \mathrm{GHz}$ ，(b) $176 \mathrm{GHz}$ ，(c) $180 \mathrm{GHz}$ and (d) $182 \mathrm{GHz}$ images. Labels are explained in the text.

The second WD affected northwest India during 18-20 February 2003. Figures 2(a) and (b) show the $700 \mathrm{hPa}$ wind at 0530 and 1730 IST on 18 February 2003. The upper air wind maximum was over northeast Arabian Sea which moved over Saurashtra during the day. The wind pattern did not change significantly in the 12 hours and therefore the moisture trajectories should be the same as streamlines. The evidence for the MCB can properly be sought in the water vapour fluxes (Bao et al 2006) integrated over the atmospheric column. In place of these fluxes, figures 2(c) and (d) record the total precipitable water $\left(\mathrm{kg} / \mathrm{m}^{2}\right)$. The moisture originating over the Arabian Sea moved to eastern UP (around $25^{\circ} \mathrm{N}, 81^{\circ} \mathrm{E}$ ) and due to the Himalayan barrier, ascended over the Himalayan foothills, also spreading towards Uttaranchal region. Over these Himalayan regions the precipitation was experienced in the morning of 19 February 2003. 

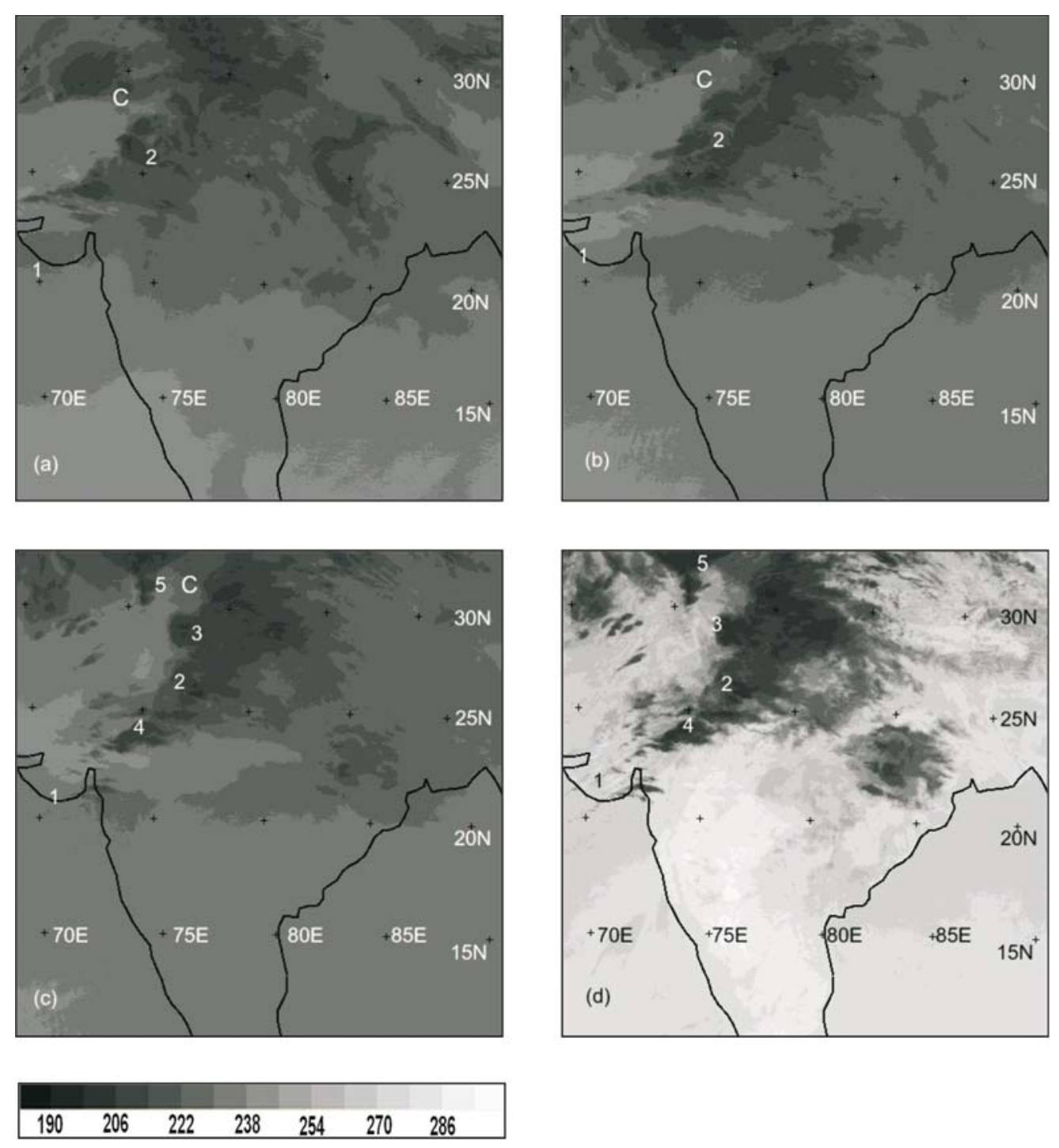

Figure 5. The evolution of the WD on 18 February 2003. (a), (b) and (c) are WV images at 0230 IST, 1130 IST and 2030 IST, (d) is the IR image at 2030 IST. Labels are explained in the text.

\section{Conveyor belts in WDs}

\subsection{Cold air intrusion on 17 April 2001}

Figures 3(a) to (d) show the evolution of the WD as viewed by the IR and WV sensors. Figures 3(a) and (b) are IR and WV images of the system at 0230 IST on 17 April. It is evident that although the IR image clearly shows the cloud tops it allows only an approximate location of the dry (cold)moist boundary. Feature (1) in figures 3(a) and (b) is the boundary. East of (1) is the moist part showing lower BT from the opaque moist layer. West of (1) is the dry part showing higher BT from the radiation upwelling from the lower levels. It is apparent that the dry-moist separation is shown better in WV than in IR. For this reason, only WV images (at 0730 and 1430 IST in figures $3 \mathrm{c}$ and $\mathrm{d}$ respectively) are shown after the 0230 IST case. A loop of IR images (not shown) shows the convection such as (3), (6) and (5) in all of figures $3(\mathrm{~b}-\mathrm{d})$, is gradually moving towards (2) along (1). It is apparent that the dry air is also intruding towards (2) in this sequence of the images. It may be noted that (6) consists of two clouds at 0230 IST which further develop and by 0730 IST become extended as seen in figure 3(c).

Figures $4(\mathrm{a}-\mathrm{d})$ are the AMSU-B images at 0230 IST of 17 April 2001. Figure 4(a) is the $89 \mathrm{GHz}$ image. This frequency is sensitive to nearsurface conditions and therefore nicely depicts geographical features such as the Gujarat coast in figure 6(a). Figures 4(b-d) are the 176, 180 and $182 \mathrm{GHz}$ images. The most important feature here is the dry-moist air boundary (1) seen faintly in figure 4(b), the $176 \mathrm{GHz}$ image. It is seen best in 
figure 4(c) $(180 \mathrm{GHz})$. In the $182 \mathrm{GHz}$ image also, (1) is seen clearly. In figure 4(b), (3) lies on a broken boundary (1) while in figures 4(c) and (d), (1) is to the west of (3) showing that the moist layer extends to the upper troposphere. As per figure 3(b) the moist layer top is close to $350 \mathrm{hPa}$ while $182 \mathrm{GHz}$ AMSU-B shows that the moisture extends to quite higher levels.

It may be noted that the upper level winds (see figure $1 \mathrm{~b}$ ) are mostly westerly, thus pushing the dry air (say between $20^{\circ}$ and $25^{\circ} \mathrm{N}$ ) eastwards and not advecting the moisture from lower latitudes towards northwest India where the axis of trough is located.

\subsection{Moist conveyor belt seen on 18 February 2003}

The analysis of the MCB is similar to the earlier subsection. Figures 5(a)-(c) are the WV image at 0230 IST, 0730 IST and 1130 IST on 18 February 2003. Figure $5(d)$ is the IR image at 1130 IST. The MCB is seen as low BT in the WV images, and originates (1) over the Arabian Sea. However, it is hard to accurately mark the extent of the conveyor belt. Only when the MCB attains sufficient altitude does it show in IR and WV images as thin cloud (2) and absorbing band (2) respectively. The MCB is demarcated as the cloud boundary. The MCB curves cyclonically at $(\mathrm{C})$. The whole band and $(\mathrm{C})$ moves toward northeast with time as is evident from figures $5(\mathrm{a})-(\mathrm{c})$ (and d). Within the curved structure, both MCB and the dry air to its left, move towards (C) where a circulation is developing.

Figures 6(a)-(d) are the 89, 176, 180 and $182 \mathrm{GHz}$ AMSU-B images at 1130 IST. In figure 6(a), BT over the northeast Arabian Sea (1) are higher than the sea to the west because of the absorption of low BT upwelling radiation by the moisture and its re-radiation at a higher BT. A curved band (2) originates from this area. In this image the curved band is not as pronounced as seen in figure $5(\mathrm{c})$. Since absorption at $89 \mathrm{GHz}$ peaks at the surface, the main moist layer is away from the surface or elevated. Similar behaviour in figure 6(b) indicates that the moist layer is below the peak absorption pressure $(700 \mathrm{hPa})$ for $176 \mathrm{GHz}$. Within the band, clouds develop towards northeast: between $25^{\circ}$ and $30^{\circ} \mathrm{N}$, a few low BT (220-240 K) features are seen (3). The clouds do not have very low BTs which are indicative of scattering by ice crystals and graupel. Therefore, these are most probably water clouds. In figures $6(\mathrm{~b})$ (d), the curved band becomes visible and the water clouds become progressively obscure, confirming their low tops. The BT in the moist band reduces progressively (figures $6 \mathrm{~b}, \mathrm{c}$ and $\mathrm{d}$ ) and the moist
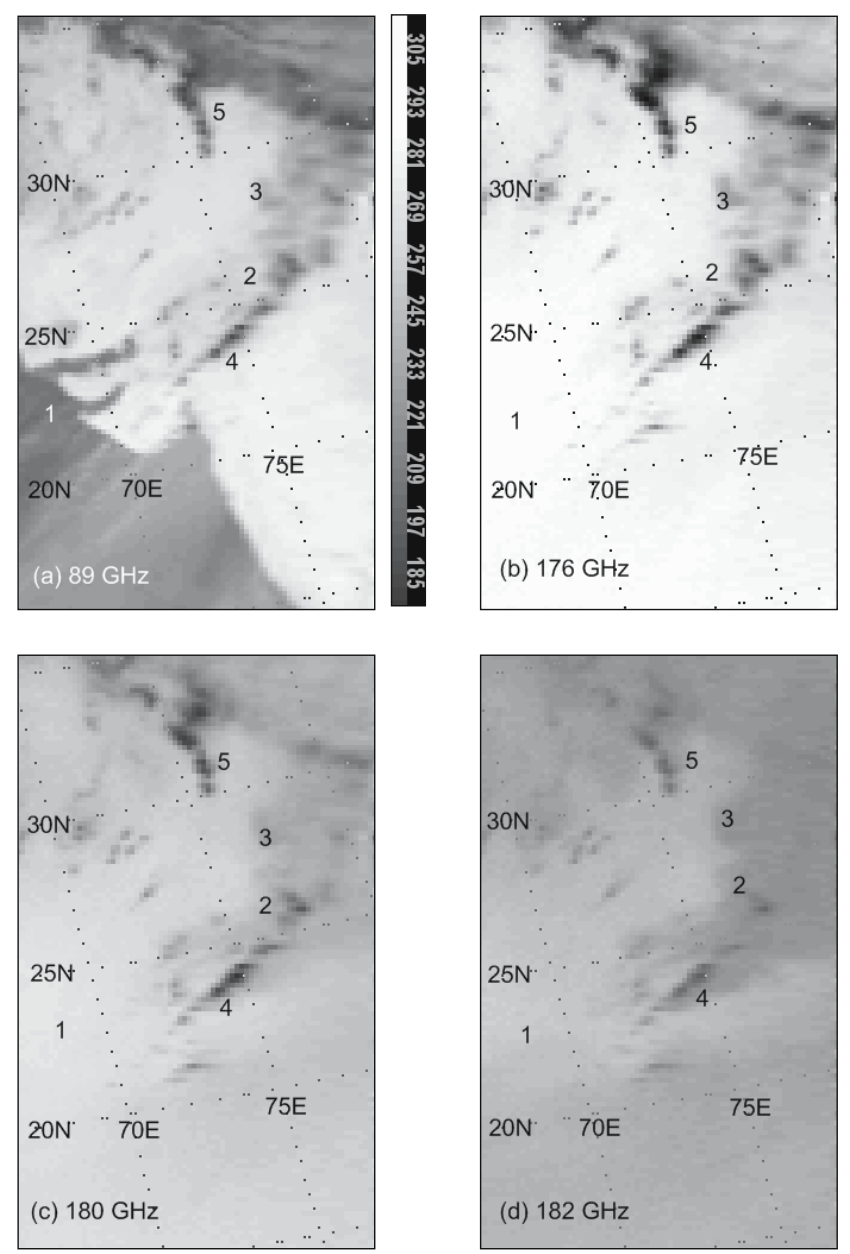

Figure 6. The AMSU-B images at 1130 IST on 18 February 2003; (a) shows $89 \mathrm{GHz}$ ，(b) $176 \mathrm{GHz}$ ，(c) $180 \mathrm{GHz}$ and (d) $182 \mathrm{GHz}$ images. Labels are explained in the text.

band is confined north of $24^{\circ} \mathrm{N}$ in figure $6(\mathrm{~d})$. This shows the ascending and deepening nature of the flow within the MCB.

\section{Mesoscale features}

\subsection{Cloud scale features on 17 April 2001}

To discuss the capabilities of the IR, WV and the AMSU-B to bring out the mesoscale features in the WDs, attention is drawn once again to figures $3(\mathrm{a}, \mathrm{b})$ and 4 . At 0230 IST, the main low BT structure (3) shows a cold top (4) at the southwestern tip and gradually increasing BTs to northeast (a range of $80 \mathrm{~K}$ in IR). In AMSU-B images, (4) has a hook-like structure with BT close to $170 \mathrm{~K}$ (as read from the data. The rest of (3) is at $220 \mathrm{~K}$. For comparison, surface BT is $280 \mathrm{~K}$ (BT range $110 \mathrm{~K}$ ). The two $\mathrm{N}-\mathrm{S}$ cloud groups (5) and (6) are clearly seen in all images. In IR and WV, individual clouds within (5) show similar BT and small spreads from the core. In figure 4(b) 

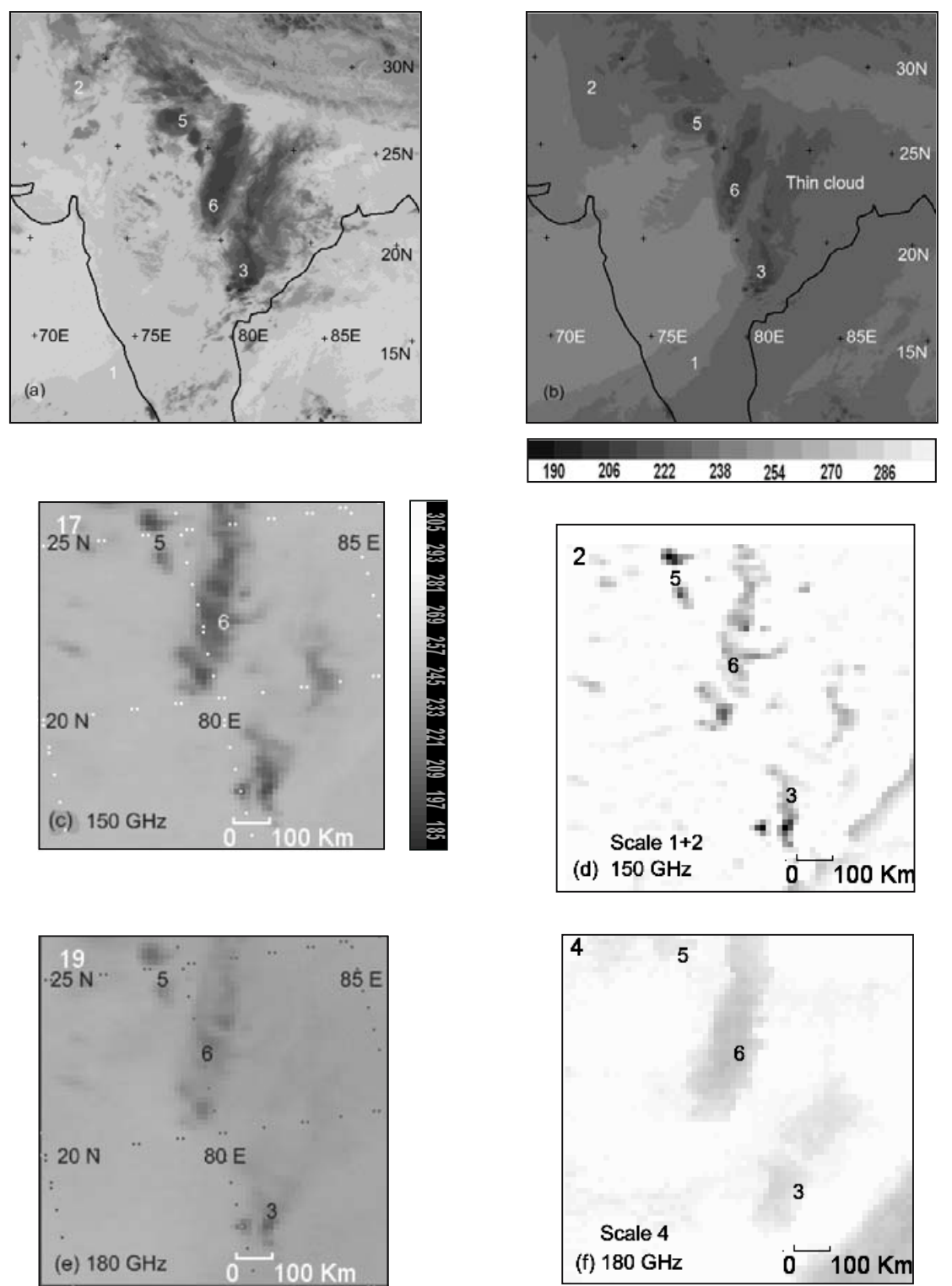

Figure 7. Illustrating the efficacy of the ATWT in separating cloud components: (a) IR, (b) WV images at 0730 IST on 17 April 2001, (c) the corresponding $150 \mathrm{GHz}$ image, (d) ATWT showing the scales $1+2$, showing convection in the cloud feature in, (e) $180 \mathrm{GHz}$ image and (f) the corresponding scale $4 \mathrm{WT}$, separating the cirrus.

$(176 \mathrm{GHz})$ the southernmost cloud shows lowest $\mathrm{BT}$, more ice scattering and highest intensity.

The convective feature (3) seen at 0230 IST on 17 April in figure 3(a) dissipated by morning. In its place the twin-cloud feature (6) in figures $3(\mathrm{a})$ and (b) developed by 0730 IST into a north-south convective feature, slightly northeast of earlier feature (3, in figure 3a). We now discuss (6). Figures 7(a) and (b) are the IR and WV images, figures 7(c) and (e) are the $150 \mathrm{GHz}$ and $180 \mathrm{GHz}$ images. Figure $7(\mathrm{~d})$ is the scale $1+2$ ATWT and figure $7(\mathrm{f})$ is its scale- 4 ATWT (scale $<128 \mathrm{~km}$ in one direction) showing the extent of the cirrus clouds. While figure 7(a) shows two cirrus topped cloud features, figure 7 (b) already shows the eastern feature to have either thin or lower (or both) cloud top. Figure 7(c) clearly shows this feature having neither water droplet nor ice scattering. The second feature in figure $7(\mathrm{c})$ shows a number of clouds of varied low BTs. These are separated clearly in figure $7(d)$. The dBTs seen in figure $7(d)$ allow an assessment of cloud top altitude. Similarly figure $7(\mathrm{f})$ clearly separates out the cirrus tops.

One useful observation about IR and AMSU-B images is made here. The IR images show a number of low cloud features (figures 3a and 5d) with BTs somewhat lower than that of the surface. These are not seen in WV images, confirming that these cloud tops have low-to-medium heights. The $89 \mathrm{GHz}$ images also do not depict these clouds, implying 

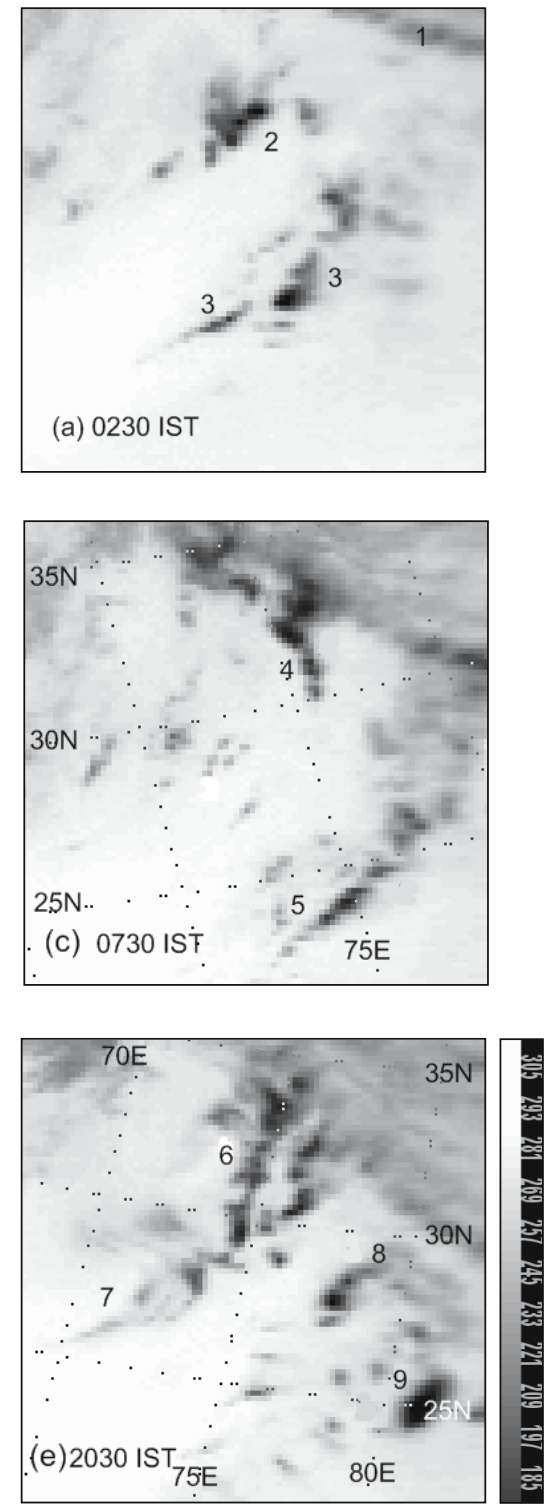
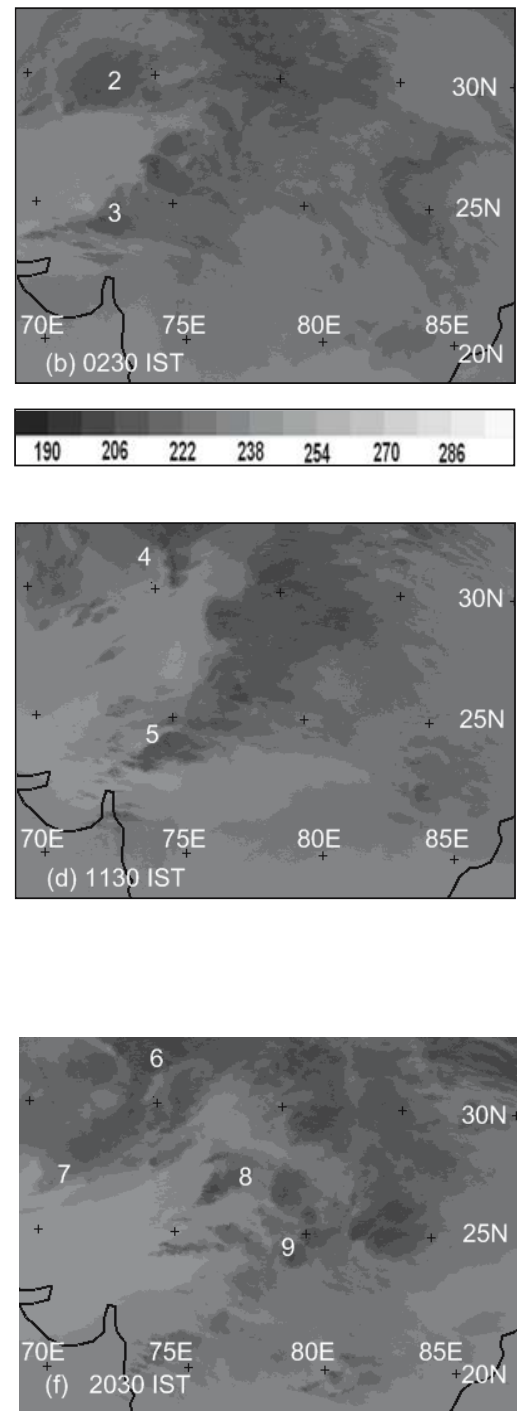

Figure 8. Mesoscale cloud lines seen in AMSU-B images. (a) At $0230 \mathrm{IST}$, (c) at $1130 \mathrm{IST}$ and (e) at $2030 \mathrm{IST}$ for $176 \mathrm{GHz}$ on 18 February 2003. (b), (d) and (f) are the corresponding IR images. The WV images do not show the large ice and water particles causing scattering in the AMSU-B images.

that there is no significant ice in these clouds to cause any scattering. Thus it may become possible to discriminate clouds with higher proportion of water.

\subsection{Mesoscale features on 18 February 2003}

The MCB at 1130 IST in figures 5(c) and (d) has been described in section 4.2. The mesoscale features in figures 5 and 6 are described here. In both figures features (3), (4) and (5) are marked. (3) is a small $\left(\sim 1^{\circ}\right)$ feature, extending to the west from the main MCB. In both IR and $\mathrm{WV}$, it has low BT and a uniform texture. In the AMSU-B data, this feature appears warmer and gradually disappears at higher frequencies. Thus (3) may be at medium altitude but has fewer hydrometeors. (4) is a line of convective clouds. In IR as well as in WV (4) is broad, mostly due to cirrus. In the AMSU-B data, this feature is linear and narrow. This shows that AMSU-B separates convective clouds from cirrus. Feature (5) is a narrow line of low BT clouds in AMSU-B data but the line progressively becomes wider northwards in IR and WV data. Thus location of convective cloud clusters are better detected with AMSU-B.

\subsection{Mesoscale convective lines on 18 February 2003}

Figures 8(a), (c) and (e) present the $176 \mathrm{GHz}$ views of the WD at 0230, 1130 and 1930 IST. This 

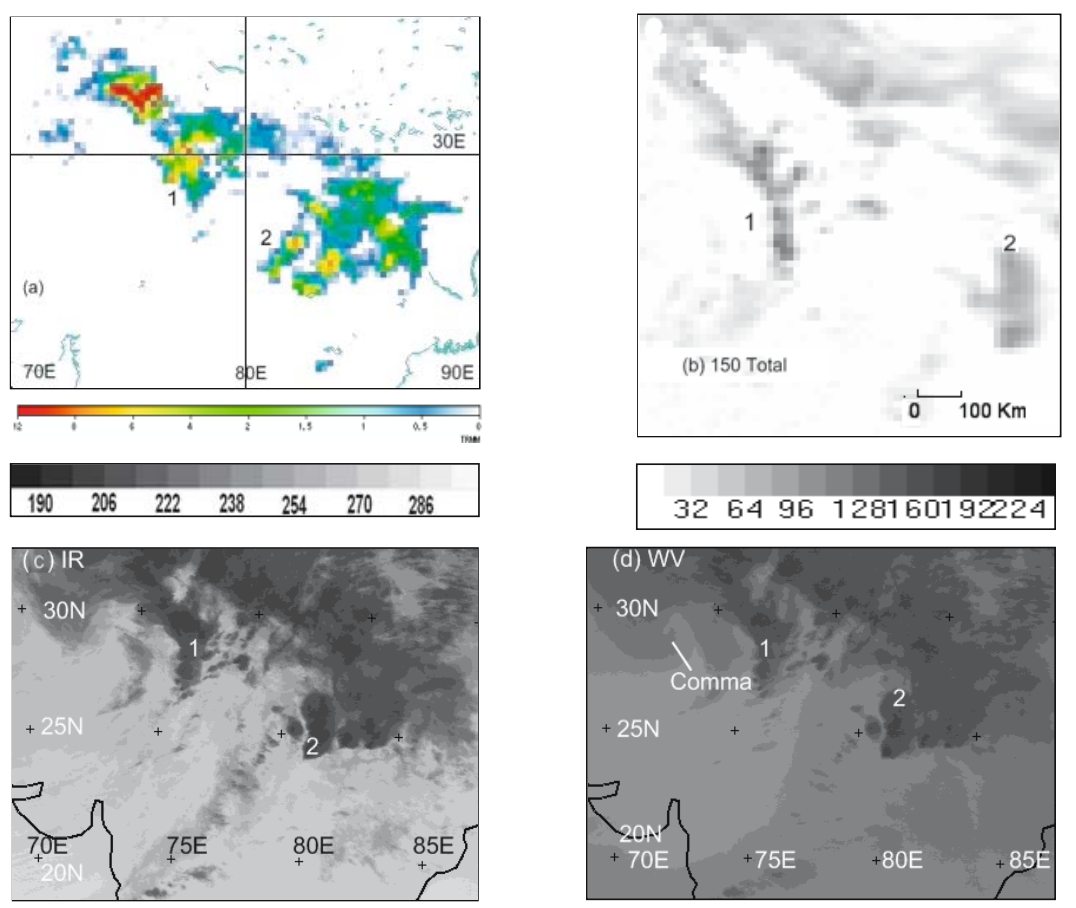

$32 \quad 6496 \quad 128160192224$

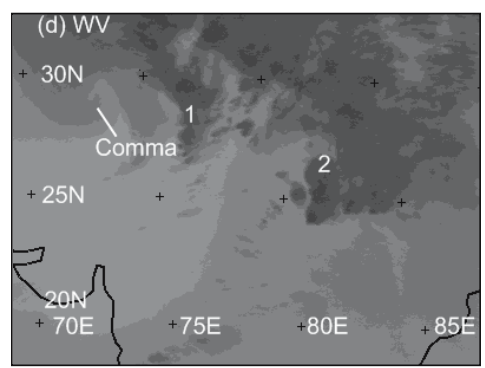

Figure 9. (a) Three hourly surface rain 3B 42 for $0.25^{\circ} \times 0.25^{\circ}$ grids from TRMM and other satellites is shown in mm during 0400-0700 IST on 19 February 2003. (b) The $150 \mathrm{GHz}$ ATWT at scales $1+2$, (c) and (d) are the corresponding IR and WV images. It is apparent that the wavelet components in (b) are better correlated to rain rates in (a) than BTs of (c) or (d).

frequency is selected to ensure that the clouds depicted extend to mid/upper troposphere as per their BTs. Corresponding WV views are seen in figures 8(b), (d) and (f). Feature 1 is the Himalayas while 2 to 9 are the mesoscale linear features. The cloud lines extend in each case to $2-400 \mathrm{~km}$. Further, their shapes are different and they are widely separated. The BTs are of the order of $165-200 \mathrm{~K}$ at $176 \mathrm{GHz}$, which is not very low. Such lines bring significant rain areas on ground. These cloud lines are not described in the classical model of extratropical cyclones. Thus these are new features, seen properly in AMSU-B images, and not reported before.

\section{Identifying rain and rain rate}

Rain was not considered so far. In AMSU-B data, low BTs in small sized features are correlated to convective (intense) rain. Low BTs seen in 89 and $150 \mathrm{GHz}$, not observed at higher frequencies, indicate warm rain from cumuli. Higher BT in $150 \mathrm{GHz}$ indicates stratiform rain from anvils. In IR images, BT of $230 \mathrm{~K}$ or lower, are indicative of cumulonimbus and therefore rain. However, cirrus of low BTs gives false indication of rain.

Unambiguous rain rate information is available from the TRMM precipitation radar (PR). However, the PR has a very narrow swath.
Therefore, the 3-hourly rain $3 \mathrm{~B} 42$ in $\mathrm{mm}$ for $0.25^{\circ} \times 0.25^{\circ}$ cells (figure 9a) accumulated during 0400-0700 IST on 19 February 2003 is compared with the ATWT applied to the AMSU-B $150 \mathrm{GHz}$ data (figure 9b) and IR and WV images (figures 9c and d respectively) at corresponding time.

The two rain features in figure 9 (a) are marked (1) and (2). At (2) in figure 9(b), the area surrounding the convection has higher BT, showing stratiform anvils. There is good likeness in the rain contours in figure $9(\mathrm{a})$, and the dBT in figure 9 (b). The dBT are of the order of $80-90 \mathrm{~K}$ for $150 \mathrm{GHz}$. The convective clouds are arranged in small $\sim 30-40 \mathrm{~km}$ clusters, as shown only by AMSU-B. Figures 9(c) and (d) show a well-defined comma-like structure. This comma structure was dissipating at the image time as evidenced by both figures $9(\mathrm{a})$ and (b). The texture of the band in figures $9(\mathrm{c})$ and (d) is uniform, implying cirrus. The rain features are mostly missed with the exception of convection at the southern edge of (2) in figures $9(\mathrm{c})$ and (d).

\section{Remarks and conclusions}

The two WDs discussed had different mechanisms driving them. The 17 April 2001 event was caused by a dry (cold) air intrusion as seen in figures 1 , 3 and 4. The 18-19 February 2003 events had an 
MCB seen in figures 2, 5 and 6 . The question to be settled is whether the IR/WV data or the AMSU-B data showed the dry-moist air boundary better.

The two IR images at figures $3(\mathrm{a})$ and $5(\mathrm{~d})$ do not show any significant dry-moist boundary, particularly over land. The WV images figures $3(\mathrm{~b})$ and 5(c) do show the dry-moist boundary. However this is seen only at the top of the moist layer, generally closer to $400 \mathrm{hPa}$ (Bader et al 1995). In figures 4 and 6 , the 89 and $150 \mathrm{GHz}$ channels depict well the moist air and the developing warm clouds (with small or none ice scattering) are seen well which are generally obscured in the higher (180, $182 \mathrm{GHz}$ ) channels. Thus in comparison there is more useful information on conveyor regions in the AMSU-B data. Only in one aspect the geostationary data is more valuable; i.e., its full spatial cover. The AMSU-B with its polar orbit and $2160 \mathrm{~km}$ swath can miss on some parts of the passing WD.

The AMSU-B BT images are able to bring out the (three dimensional) structure of the WDs better than the IR and WV images. The locations of mesoscale cloud lines seen in the AMSU-B images and covered beneath the cirrus are one case of importance to weather analysis.

Comparison of the AMSU-B and TRMM based 3-hourly rain data shows that large depressions in BT in AMSU-B data (tentatively $\sim 80 \mathrm{~K}$ ) corresponded to rain estimated by TRMM in the 19 February 2003 early morning case. Further, correlation between the rain regions and the ATWT (of $150 \mathrm{GHz}$ channel) was better than with the IR and WV images.

We conclude that AMSU-B and multi-scale analysis together give added advantages to the analysis of weather produced by the geostationary IR and WV data. We hope that in the near future, MADRAS and Saphir (onboard MeghaTropiques), AMSU-B and MHS would enrich the practice of weather analysis.

\section{Acknowledgements}

Bhupendra Raut is acknowledged for his many faceted help. Level 1b AMSU-B data was obtained from NOAA CLASS web archive. IR and WV digital data were obtained from EUMETSAT archive. Figures 1 and 2 have been downloaded from the NOMADS3 server of NCEP, NOAA, USA. This work was funded by ISRO grant GOI 419 at University of Pune.

\section{Appendix}

A very brief description of the $\grave{a}$ trous transform is given below. Let $C_{0}(k)$ be the sampled dataset. Let a scaling function $\Phi(x)$ be a low pass filter.
The wavelet coefficients $W_{i}(k)$ at scale $i$ are found using successive approximation:

$$
W_{i+1}(k)=C_{i}(k)-C_{i+1}(k) .
$$

$C_{j}$ are given by $C_{j}(k)=\Sigma_{l} h(l) C_{J-1}\left(k+2^{j-1} l\right)$.

In turn $h(k)$ are derived from:

$$
\frac{1}{2} \Phi\left(\frac{x}{2}\right)=\Sigma_{l} h(l) \Phi(x-l) .
$$

As $i$ increases, the $k$ th pixel is convolved with those at the spacing of $2^{i-1}$. This in effect allows the larger spatial or temporal wavelengths to be brought out and separated. Thus all $C_{i}$ can be shown as graphs (or images in two dimensions). This is termed multi-resolution analysis.

$$
C_{0}(k)=C_{\mathrm{Rem}}(k)+\Sigma_{j} W_{j}(k),
$$

where $C_{\mathrm{Rem}}(k)$ is the smooth remainder signal array.

The scaling function for the $\grave{a}$ trous analysis is selected for a good smoothing performance. The convolution mask used is given as $h_{B 3}(l)=$ $\{0.0625,0.25,0.375,0.25,0.0625\}$. In case of a two-dimensional image, the filter given above is used first on columns and then on the rows of the image.

\section{References}

Bader M J, Forbes G S, Grant J R, Lilly R B E and Waters J 1995 Images in Weather Forecasting, Cambridge University Press, 493 pp.

Bao J-W, Michelson S A, Neiman P J, Ralph F M and Wilczak J M 2006 Interpretation of enhanced integrated water vapor bands associated with extratropical cyclones: Their formation and connection to tropical moisture; Mon. Wea. Rev. 134(4) 1063-1080.

Browning K A 1986 Conceptual models of precipitation systems; Wea. Forecasting 1 23-41.

Gheiby A, Sen P N, Puranik D M and Karekar R N 2003 Thunderstorm identification from AMSU-B data using an artificial neural network; Met. Appl. 10(4) 329-336.

Goodrum G, Kidwell K B and Winston W 2000 The NOAA $K L M$ users' guide; NOAA US Department of Commerce New York, NY, USA.

Holton J R 1992 An Introduction to Dynamic Meteorology, Academic Press.

Kidder S Q and Vonder Haar T H 1995 Satellite Meteorology: An Introduction; Academic Press, 466 pp.

Knippertz P and Martin J E 2007 A pacific moisture conveyor belt and its relationship to a significant precipitation event in the semi-arid southwestern United States; Wea. Forecasting 22(1) 125-144. 
Kummerow C, Olson W S and Giglio L 1996 A simplified scheme for obtaining precipitation and vertical hydrometeor profiles from passive microwave sensors; IEEE Trans. Geosci. Remote Sensing 341213.

Muller B M, Fuelberg H E and Xiang X W 1994 Simulation of the effect of water vapour, cloud liquid water and ice on AMSU moisture channel brightness temperatures; J. Appl. Meteor. 33(10) 1133.

Puranik D M and Karekar R N 2004 Classification of thunderstorms over India using multi-scale analysis of AMSU-B images; J. Appl. Meteor. 43(4) 595.

Rao Y P and Srinivasan V 1969 Discussion of typical weather situations: Winter western disturbances and their associated features; Forecasting Manual, IMD, India, Part III, I.1.
Roca R, Brogniez H, Picon L and Desbois M 2001 High resolution observations of free tropospheric humidity from METEOSAT over the Indian Ocean, MEGHATROPIQUES 2nd Scientific Workshop, 2-6 July 2001, Paris, France.

Shensa M J 1992 Discrete wavelet transforms: Wedding the ' $\grave{a}$ trous' and Mallat algorithms; IEEE Trans. Sig. Proc. 402464.

Skofronick-Jackson G M, Gasiewski A J and Wang J R 2002 Influence of microphysical cloud parameterisations on microwave brightness temperatures; IEEE Trans. Geosci. Rem. Sens. 40(1) 187.

Starck J-L, Murtagh F and Bijaoui A 1998 Image Processing and Data Analysis; Cambridge University Press, $284 \mathrm{pp}$. 